\title{
Exhaust emissions of particulate matter from light-duty vehicles - an overview and the current situation
}

Emissions of particulate matter associated with the use of light-duty vehicles are an increasingly important topic, with more and more political attention focused on this issue. Now that direct injection Diesel engines feature DPFs, particle emissions from other engine types operating on other fuels are also of great interest. This paper discusses the phenomenon in general, briefly reviews worldwide legislation and emissions limits and presents the results of a laboratory test programme measuring the particle emissions from a range of vehicles. The experimental programme showed that the engine/fuel type has a greater impact on particle emissions than the test conditions.

Key words: particulate matter, exhaust emissions, PM, PN, chassis dynamometer testing

\section{Introduction}

Exhaust emissions of particulate matter are coming under increasing scrutiny as a form of pollution with wideranging negative impacts. For decades, discussion of vehicular particulate emissions was limited to exhaust emissions from vehicles with CI (compression ignition - Diesel) engines; this situation has changed and both non-exhaust emissions and exhaust emissions from vehicles with SI (spark ignition - petrol) engines are the subject of intensive research efforts: the advent of petrol engines with direct injection (direct injection spark ignition, DISI) - an engine type prone to somewhat more Diesel-like behaviour regarding particulate emissions - is a major focus.

The specifics of particle formation and release during the combustion cycle are a function of the engine type, fuel chemistry, oil type/chemistry and the engine operating point (including the temperature of the engine and its elements). The chemistry of exhaust particulates depends on the fuel type, oil type and of course engine operating conditions and the type, condition and thermal state of the exhaust gas aftertreatment system (if present). Even where the fuel contribution is zero (during fuel cut-off or when using a zero carbon fuel such a hydrogen), particulate emissions are still detectable, with such emissions deriving from engine oil and metals originating from wear of engine components. Aftertreatment systems dedicated to removing (generally trapping and later destroying) particulate emissions are now commonplace on automotive Diesel engines thanks to the roll-out of DPFs; for the time being, vehicles with other engine types are typically not fitted with such devices, although the petrol equivalent to a DPF (GPF) will be required from September 2017 onwards in the EU.

Legal limits for any type of exhaust emission immediately raise the question of how those emissions will be measured. For decades, a relatively simple laboratory technique has been used, in which a known portion of the diluted exhaust gas is drawn through filter(s) which is (are) weighed before and after the test, generating a particle mass (PM) result. This method remains the main means of enforcement worldwide, although its accuracy is inversely proportional to the quantity of particulate emitted. Increas- ingly stringent emissions legislation aims to reduce exhaust gas particulate levels - and not only for vehicles featuring Diesel engines. Various authorities have set limits for the mass of particulate (PM) emitted over a legislative driving cycle and the EU has added particle number (PN) limits, now applicable to vehicle with DISI engines. Additionally, there is considerable interest in particulate emissions from engine types traditionally assumed to have negligible particulate emissions - port fuel injected vehicles running on petrol (and even LPG and CNG). In addition to local differences in terms of whether PM and PN (or just PM) is used as the metric of control, test procedures also have an impact on the particle emissions profile and thereby on the final $\mathrm{PM} / \mathrm{PN}$ results.

An obvious starting point is the driving cycle specified in the legislation: the newly-introduced WLTP with its near-eponymous test cycle (WLTC) is a marked departure from the current EU test cycle (the NEDC). While the new cycle has been designed more with improved $\mathrm{CO}_{2} /$ fuel consumption measurements in mind, it will also be used to measure regulated emissions, including PM and PN and the current Euro 6 limits will not be modified to allow for the new driving cycle. The first phase of both driving cycles can be of special interest - both cycles commence from a cold start and cover between $3 \mathrm{~km}$ and $4 \mathrm{~km}$ during their respective first phases, but with very different driving profiles. However, apart from the driving cycle, other factors are also relevant (the road load simulation settings applied on the chassis dynamometer, gearshift strategy, test temperature, etc.).

A wide body of work exists on light duty vehicular particulate emissions measured under laboratory conditions. Recently, some studies have begun to report on-road particulate emissions. In recent years virtually all authors have come to employ the PN metric in their investigations, as well as results generated by non-legislative pieces of equipment and techniques. May and co-workers [17] reported on gaseous and solid pollutants measured over various chassis dynamometer cycles, measuring PM and PN via the European legislative methods. They reported impacts on both PM and PN for their test vehicles as the driving cycle 
and inertia settings were changed and the results indicated a significant contribution to PN from cold start. Mamakos and Manfredi [15] tested a range of petrol vehicles over the NEDC and CADC (a demanding driving cycle which shares some characteristics with the WLTC), employing a range of advanced particulate measurements strategies. They included a bifuel petrol/CNG vehicle in their studies (NEDC test cycle only), which was found to emit significantly lower numbers of solid particles of diameter $>23 \mathrm{~nm}$ when running on gaseous fuel than on petrol. Anderson et al. [3] subjected two Euro 6 diesel vehicles to a range of chassis dyno tests, reporting that PM emissions were always under $1 \mathrm{mg} / \mathrm{km}$; PN emissions varied between test cycles and inertia settings with higher PN emissions over the NEDC than the WLTC. Cédric et al. [7] tested several Euro 5 Diesel-DPF and DISI vehicles over multiple driving cycles and reported that cold start was responsible for both a high proportion of $\mathrm{PN}$ results and a high proportion of the uncertainty associated with those results. Wei et al. [27] also report finding cold start and high load during the first 200 seconds to be a massive contributor to particulate emissions (measured as PM in their study). They also mentioned significant changes in particle composition as a function of the driving cycle employed, as evidenced by the elemental carbon/organic carbon split.

In their recent study Giechaskiel et al. [11] tested a range of engine technologies both on the chassis dyno and on the road, measuring solid PN using a range of sampling configurations. Vehicle mass (inertia) was varied and was found to have an impact on emissions from a vehicle with a DISI engine. Zhang et al. [29] measured size-classified particle number from direct- and indirect-injection petrol vehicles over the NEDC, again reporting cold start and acceleration to be significant contributors to the PN budget over the entire driving cycle. Whelan et al. [28] quantified the high particulate emissions associated with cold start and warmup of a DISI engine - yet noted that some $95 \%$ of the particles (by number) were too small to be measured using the legislative PN setup. Some recent research (e.g. [12], [20], and references therein) has focused on direct-injection petrol engines and the benefits of fitting particulate aftertreatment devices (GPFs) to those vehicles, yet as of the time of writing, vehicles fitted with such devices have not yet been rolled out and are generally not market-available.

In addition to legislative measurements/devices, a range of tools is available for R\&D purposes, quantifying particles (or some fraction thereof) in terms of number, mass and size distribution (see $[2,11,18]$ and references therein for discussions of such hardware and its usage in laboratory testing; see [13] for some inter-instrument comparisons). The experimental section of this paper aims to contribute to the discussion in the field by presenting data obtained from exhaust emissions testing on a range of in-use engine/fuel type combinations, including a vehicle running on $\mathrm{CNG}$, over the NEDC and WLTP, using European legislative techniques $(\mathrm{PM} / \mathrm{PN})$ and an additional non-legislative particulate emissions measurement technique (namely an AVL Microsoot sensor). The main variables in the study were the engine/fuel type (varied by test vehicle) and the driving cycle (NEDC, WLTC). Following the test procedures asso- ciated with the two test cycles also necessitates using different gearshift points and so the relationship between the speed trace and the engine operating points is another variable. The impact of the chassis dynamometer inertia setting was also investigated. The test vehicle with a Stop\&Start system was tested with that system both enabled and disabled. Furthmore, in some cases a non-legislative measurement was performed - AVL's Microsoot sensor (MSS) is a device which measures the mass (not number) concentration of solid particles in real time [21], generally sampling raw exhaust. In the experimental work reported in this paper, such a device was used for some testing and the results are briefly compared to both filter-based PM results and PN results.

Particle emissions from engines have been investigated for decades and regulated since the 1990s (in the EU). Particulates have a range of negative impacts on air quality, human health and the natural and built environments and emissions standards have sought to dramatically reduce emissions of particulates over time. (See [17] and references therein for a discussion of the topic in general and some notes on its history.) The EU was the first jurisdiction to mandate the measurement of solid particle number (PN) and set an emissions limit: $6.0 \times 10^{11}$ particles $/ \mathrm{km}$. This legal requirement means that exhaust emissions laboratories have to be equipped with a condensation particle counter (CPC) meeting the requirements of UNECE Regulation No. 83 [26]. (See [3] and [7] for detailed discussions of legislative PN measurement technique.)

Emissions results (and limits) are distance-specific, meaning they are divided by the distance travelled by the vehicle while the emission took place. During the course of a driving cycle, the vehicle accumulates distance covered according to the integrated speed trace and in doing so emits combustion products, including particulate. At any given moment during the test, these two parameters are usually both evolving - the balance between the instantaneous rate of change of these two factors shall be termed $E$ and defined as follows:

$$
\mathrm{E}=\frac{\delta \mathrm{PN}}{\delta \mathrm{S}}
$$

where $\mathrm{S}$ is the cumulative displacement from the origin i.e. the distance travelled by the vehicle during the period considered (for example, time elapsed since engine startup).

As $\delta \mathrm{S}$ is simply speed, a scalar quantity and negative PN exhaust emissions can be considered unmeasurable, $\mathrm{E}$ only takes values $\geq 0$. When the vehicle is stationary, but the engine is still running (idling) E reaches $\infty$. A driving cycle which consisted only of idling would therefore generate a result of $\infty \# / \mathrm{km}$. A driving cycle consisting mainly of idling would likely generate a high PN emission result, even though mean engine load and the amount of fuel consumed would be low. Where present, stop \& start (idle stop) systems can have a noticeable impact on PN emissions; self-evidently, for a cycle with no idling at all, the impact of such a system would be nil. Stop events in the cycle speed trace not only involve idling; they also necessitate another pull away event, forcing the usage of low gears to accelerate back up to speed, causing increased fuel con- 
sumption and often causing elevated PN emissions. However, fuel-intensive acceleration events warm up the engine more rapidly than constant speed driving and so the proportion of idling is not sufficient information to predict the particulate emissions occurring over a cold start driving cycle.

At any given point in the cycle (i), the values of E given by (1) may be integrated, thereby giving PN accumulated from $t=0$ up to point $i$, divided by the distance covered from $t=0$ up to point $i$ ( $E^{\prime}$, as defined in equation 2 ):

$$
\mathrm{E}^{\prime}=\sum_{0}^{\mathrm{i} \mathrm{PN}} / \sum_{0}^{\mathrm{i}} \delta \mathrm{S}
$$

Since PM samples collected on filters only have a resolution of one result per test (or one result per phase), PN results collected at $1 \mathrm{~Hz}$ (or more) have a clear advantage in terms of their utility for this type of analysis.

Up to now, particulate emissions have only been regulated under laboratory test conditions over well-defined and widely known test cycles; the notable exception to this is the EU and perhaps some other markets, where on-road limits will be introduced (see comments below and in later sections of this paper).

A summary of these emissions limits and the associated test cycles is presented in Table 1; it is worth recalling that many further countries implement the legislation used in the EU and USA.

Table 1. A summary of particulate emissions control strategies in selected automotive markets

\begin{tabular}{|l|l|l|l|}
\hline $\begin{array}{l}\text { Jurisdiction / legisla- } \\
\text { tive stage }\end{array}$ & $\begin{array}{l}\text { PM } \\
{[\mathrm{mg} / \mathrm{km}]}\end{array}$ & PN [\#/km] & $\begin{array}{l}\text { Applicable test } \\
\text { cycle }\end{array}$ \\
\hline EU / Euro 6b & 4.5 & $\begin{array}{l}6.0 \times 10^{11} \\
\text { for CI; } \\
6.0 \times 10^{12} \\
\text { for DISI }\end{array}$ & NEDC \\
\hline EU / Euro 6c & 4.5 & $6.0 \times 10^{11}$ & NEDC $\rightarrow$ WLTC \\
\hline EU / RDE & $\begin{array}{l}\text { Not } \\
\text { measured }\end{array}$ & $9.0 \times 10^{11}$ & $\begin{array}{l}\text { RDE-compliant } \\
\text { road route }\end{array}$ \\
\hline $\begin{array}{l}\text { EPA / Tier II } \\
\text { "full useful life", } 8 \\
\text { bins) }\end{array}$ & $0.0-$ & None & FTP-75 \\
\hline $\begin{array}{l}\text { CARB / Exhaust } \\
\text { Mass Emission Stand- } \\
\text { ards (2015) }\end{array}$ & 6.43 & None & FTP-75 \\
\hline $\begin{array}{l}\text { CARB / Particulate } \\
\text { Standards } \\
\text { (2017-) }\end{array}$ & 1.86 & None & FTP-75 \\
\hline $\begin{array}{l}\text { CARB / Particulate } \\
\text { Standards } \\
\text { (2027-) }\end{array}$ & 0.62 & None (?) & FTP-75 \\
\hline $\begin{array}{l}\text { Japan / Post New } \\
\text { Long Term }\end{array}$ & 5.0 & None & JC08 $\rightarrow$ WLTC \\
\hline
\end{tabular}

\section{Recent laboratory testing conducted at BOSMAL}

\subsection{Aim \& types of test vehicles used}

A series of tests were conducted in late 2016 in order to characterize the emissions from vehicle types other than Diesel with DPF and to compare emissions. The motivation for this was the widespread introduction of DPFs to Diesel and the incoming Diesel-equivalent PN limit for DISI engines. A further motivation was the incoming requirement for RDE testing of vehicles with a CF of 1.5; while no RDE testing is reported in this paper, laboratory test cycles such as the relatively dynamic and demanding WLTC can be informative as regards that topic. Basic data of the test vehicles is given in Table 2 .

Table 2. Basic data of the test vehicles used in this study

\begin{tabular}{|l|l|l|l|l|}
\hline Vehicle No. & 1 & 2 & 3 & 4 \\
\cline { 1 - 5 } Parameter & PC & PC & PC & PC \\
\hline Engine type & DISI & CI & SI, CNG & CI \\
\hline Displacement [dm $\left.{ }^{3}\right]$ & $\sim 1.5$ & $\sim 2$ & $\sim 1$ & $\sim 1.5$ \\
\hline $\begin{array}{l}\text { Exhaust emission stand- } \\
\text { ard }\end{array}$ & Euro 6 & Euro 5 & Euro 6 & Euro 6 \\
\hline $\begin{array}{l}\text { Aftertreatment system } \\
\text { type }\end{array}$ & TWC & $\begin{array}{l}\text { DOC+ } \\
\text { DPF }\end{array}$ & TWC & $\begin{array}{l}\text { DOC+ } \\
\text { DPF }\end{array}$ \\
\hline $\begin{array}{l}\text { Transmission type, } \\
\text { number of gears }\end{array}$ & Man, 6 & Auto, 7 & Man, 5 & Man, 5 \\
\hline $\begin{array}{l}\text { Approx. mileage at start } \\
\text { of 2testing [km] }\end{array}$ & 15,000 & 20,000 & 3,000 & 2,500 \\
\hline $\begin{array}{l}\text { Particulate measurement } \\
\text { systems used }\end{array}$ & $\begin{array}{l}\text { PM, } \\
\text { PN }\end{array}$ & $\begin{array}{l}\text { PM, } \\
\text { PN }\end{array}$ & $\begin{array}{l}\text { PM, PN, } \\
\text { MSS }\end{array}$ & $\begin{array}{l}\text { PM, } \\
\text { PN }\end{array}$ \\
\hline Additional variables & $\begin{array}{l}\text { S\&S } \\
\text { ON / } \\
\text { OFF }\end{array}$ & $\begin{array}{l}\text { S\&S } \\
\text { ON / } \\
\text { OFF }\end{array}$ & $\begin{array}{l}\text { Also } \\
\text { tested at } \\
\text { constant } \\
\text { speed }\end{array}$ & $\begin{array}{l}\text { Dyno } \\
\text { inertia } \\
\text { varied }\end{array}$ \\
\hline
\end{tabular}

\subsection{Experimental details}

A series of tests was carried out in a climate controlled exhaust emissions laboratory. This test facility meets all the demands of EU Euro 5/6 level legislative requirements, as well as the stipulations of GTR 15 [25]. Each of the test vehicles was tested four times over the driving cycles (but only twice for the constant speed cycle). The vehicles were preconditioned on the chassis dynamometer according to the test procedure associated with each test cycle; external battery charging was performed only before the first preconditioning cycle (and not between emissions tests). The soak time (at $20-25^{\circ} \mathrm{C}$ ) between periods of engine operation was at least 11 hours. The CI vehicles' DPFs were regenerated before commencing testing on a given test cycle (so the first test on each cycle occurred with a very similar state of DPF loading). Oil levels and the onboard computer's estimated oil degradation level were checked to ensure that differences between test runs were as low as reasonably practicable. The Euro 6 CI vehicle with an LNT $\mathrm{DeNO}_{\mathrm{x}}$ system was driven over an extended preconditioning cycle to make sure that the system was stable before starting testing.

All testing reported here was performed at $23^{\circ} \mathrm{C}$ and $45-50 \%$ relative humidity, thereby satisfying the ambient condition requirements of the NEDC (current EU legislation [26]), as well as the WLTP (GTR15 [25]).

Three test cycles were employed: the NEDC, the WLTP and, for vehicle 3 only, constant speed $\left(90 \mathrm{~km} / \mathrm{h}\right.$ in $5^{\text {th }}$ gear). All four test vehicles were tested on the same chassis dynamometer (AVL ROADSIM 48" MIM 4x2 LIGHT TRUCK - twin axle, single roll); emissions measurement and analysis was performed using a Horiba CVS-CFV sampling system, together with a dilution tunnel (Horiba DLT-7020)and a set of Horiba MEXA-7400HRTLE exhaust analysers for measurement of gaseous emissions. Those results are not presented here, but were used to en- 
sure test-to-test repeatability and to look for the tell-tale signs of regeneration of the DPF and $\mathrm{DeNO}_{\mathrm{x}}$ systems. All the aforementioned devices are controlled by the Horiba VETS-7000NT management system.

Legislative particulate emissions (both mass and number) were measured in accordance with the requirements of [25] and [26]. Specifically, for quantification of PM a single TX40 filter was used to collect a portion of the diluted exhaust gas. (TX40 filters are not without their disadvantages, namely artefacts caused by gaseous emissions which become significant at low particulate emissions levels [8], but their use is permitted according to European legislation $[25,26]$ and they remain widely used in the automotive industry.) A single TX40 filter was used per test (and not one filter per phase), in line with [25] and [26] and thereby maximising the filter payload and reducing weighing errors. Following the emissions test, the filter was immediately returned to the climate-controlled balance room and allowed to stabilise for at least an hour (between 65 and 80 minutes) before being weighed, again in line with [25] and [26]. For the vehicle running on CNG, this stabilisation period was substantially extended, owing to the increased water content in the exhaust gas and the lower level of particulate emission. For quantification of PN in full accordance with [25] and [26], a Horiba MEXA2000SPCS condensation particle counter (CPC) was used. This device features two-stage internal dilution and a volatile particle remover operating at $350^{\circ} \mathrm{C}$; as stipulated by EU legislation, it is specifically designed to measure only solid particles of diameter $>23 \mathrm{~nm}$ - see [25] and [26] for details on the response curve and the sample pre-treatment system.

Non-solid (volatile or semi-volatile) particle emissions are measurable using other types of measurement systems, but the results they generate are highly dependent on the sampling procedure [27, 28] (temperature, dilution, residence time) - that fact is the main reason behind their exclusion from legislative PN measurements. The CPC itself has a recommended upper range of 10,000 particles $/ \mathrm{cm}^{3}$; the CPC system's dilution settings were adjusted such that the maximum particle concentration measured during a test did not exceed 4,000-5,000 particles $/ \mathrm{cm}^{3}$. As required by [25] and [26], the PM and PN samples were taken from the emissions system's dilution tunnel at a point where the exhaust gas and the dilution air are very well mixed. Where used, the AVL Microsoot sensor was connected directly to the vehicle's tailpipe (not to the dilution tunnel) and the internal dilution settings were adjusted such that the maximum measured gravimetric concentration did not exceed approximately $40 \mathrm{mg} / \mathrm{m}^{3}$ during any test (the device's limit is $50 \mathrm{mg} / \mathrm{m}^{3}$ ). For the NEDC and WLTP tests, four repeat tests were carried out; two repetitions were deemed sufficient for the constant speed testing, as repeatability was much higher than for the cold start driving cycles. The results presented here refer to the arithmetic mean values obtained from the repeat emissions tests $(n=4 ; n=2)$.

\subsection{Results and analysis}

All vehicles were found to meet the applicable EU emissions limits when tested over the NEDC. Vehicle 3 (bifuel: petrol/CNG, type approved in the EU) is not subject to any particulate emissions limits, but in any case it met the stringent Euro 6 limits for vehicles with CI engines. Testto-test repeatability of gaseous emissions (most importantly $\mathrm{CO}_{2}$ ) was well within normal limits, with low coefficients of variance. Given the stability of the gaseous emissions, particulate emissions are presented here on an "as measured" basis - i.e. no additional repeat tests were carried out, regardless of test-to-test variations in particulate emissions. Results are presented separately for each vehicle.

\subsubsection{Vehicle 1}

Vehicle 1's legislative particulate emissions were elevated, but within Euro 6 emissions limits when tested over the NEDC. Emissions of both PM and PN (Figures 1 \& 2) were significantly higher over the WLTP than the NEDC; PM exceeded the Euro 6 limit over the WLTP. The Stop\&Start system showed a clear advantage: when the engine was allowed to stop at idle ("S\&S ON") PM emissions were reduced by $47 \%$ over the NEDC and $22 \%$ over the WLTP; PN emissions were reduced by $30 \%$ over the NEDC and 9\% over the WLTP compared to when the engine ran at idle ("S\&S OFF"). The greater advantage of the Stop\&Start system in reducing particulate emissions over the NEDC than the WLTP is in line with the former cycle's higher proportion of idling. That being said, the total proportion of idle time is not the only factor: the timing and number of engine restarts and the warm-up penalty caused by engine shutdown at idle also influence the relative PM and PN results; this applies whether the Stop\&Start system is active or inactive.

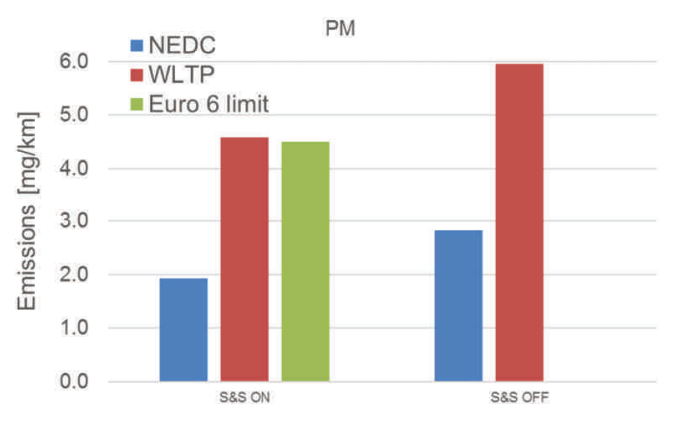

Fig. 1. PM emissions from vehicle 1

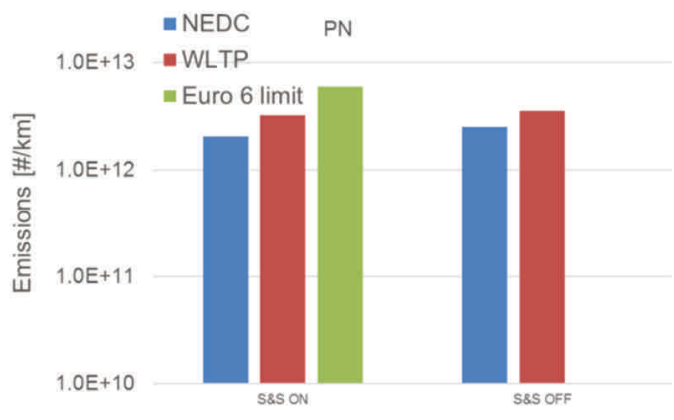

Fig. 2. PN emissions (solid particles only) from vehicle 1 (note the $\log _{10}$ scale)

The magnitude of the emissions from vehicle 1 are reasonably similar to those reported elsewhere [7, 15]. Importantly, when Stop\&Start was turned on, the vehicle met the Euro 6 PN limit over the WLTC, despite (presumably) not being calibrated to that cycle. 
Particle number measurements were recorded at $1 \mathrm{~Hz}$ and the mean traces from the three repeat tests were taken for analysis, as shown in Figure 3.

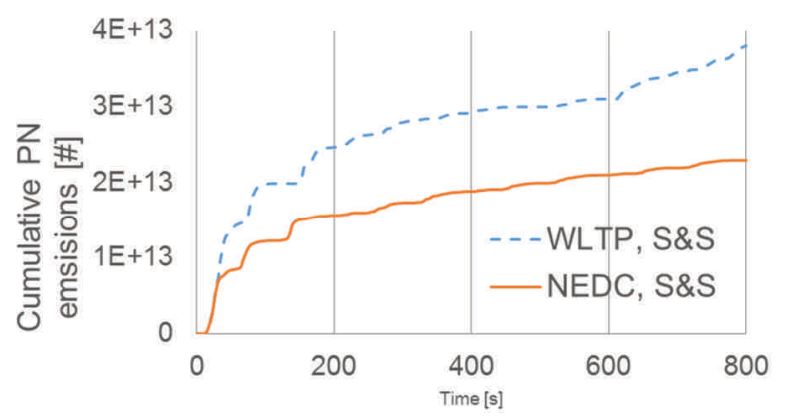

Fig. 3. Cumulative PN emissions (solid particles only) from vehicle 1

As Figure 3 shows, the first 800 seconds of the PN emission profile for the two test cycles differ significantly. However, it should be recalled that emissions limits are distance specific $[/ \mathrm{km}]$ and so the distance travelled by the vehicle has just as great an impact on the final result as the emissions themselves. Dividing the instantaneous cumulative emissions by the instantiates cumulative distance covered revealed a different tendency, as shown in Figure 4. The higher load of the first ramp of the WLTC Low causes elevated absolute PN emissions compared to the NEDC's UDC phase, but on the other hand there are few stop events and distance is accumulated rather quickly. The result of this is that distance-specific PN emissions rapidly fall to a lower level than those of the NEDC. The length of the first 'ramp' (sub-trip) is important, especially where a Stop\&Start system is present - over the WLTC the engine was sufficiently warmed up to allow the Stop\&Start system to shut down the engine at the earliest opportunity (98 seconds), whereas over the NEDC this vehicle's engine does not shut down at idle until the second opportunity to do so (which also happens to occur at around 98 seconds). From that point onwards, the Stop \& Start system shuts the engine down at every available opportunity and the distancespecific emissions traces over the remainder of the cycle are broadly similar (though not identical).

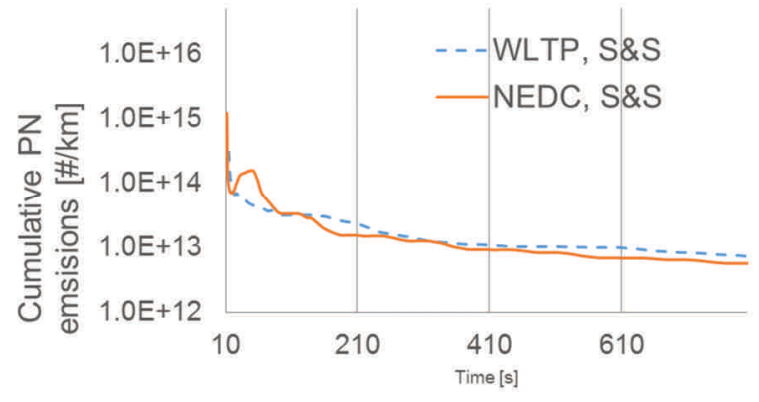

Fig. 4. Distance-specific cumulative PN emissions (solid particles only) from vehicle 1, calculated according to (2). The first 10 seconds have been excluded as distance-specific emissions during that period are $\infty$

While engine restarts themselves do generate particulates, which add to the PM and PN emitted over the entire test, these startup peaks become progressively smaller as the engine warms up, such that over the entire cycle (both the NEDC and the WLTP) the positive impact of the Stop\&Start system on legislative particulate emissions from vehicle 1 is indisputable. Given that vehicle 1 did not feature a dedicated particulate aftertreatment system (GPF), these exhaust emissions trends should be strongly related to the engine out particulate flux, since the potential for substantial accumulation-and-release cycles in the exhaust system is likely to be limited.

\subsubsection{Vehicle 2}

Vehicle 2's particulate emissions were low, due to it being a Euro $5 \mathrm{CI}$ vehicle fitted with a fully-functioning DPF. However, post-DPF emissions were measurable and differences in PM and PN emissions between the two test cycles used (NEDC, WLTP) were noted, as shown in Figures 5 and 6.

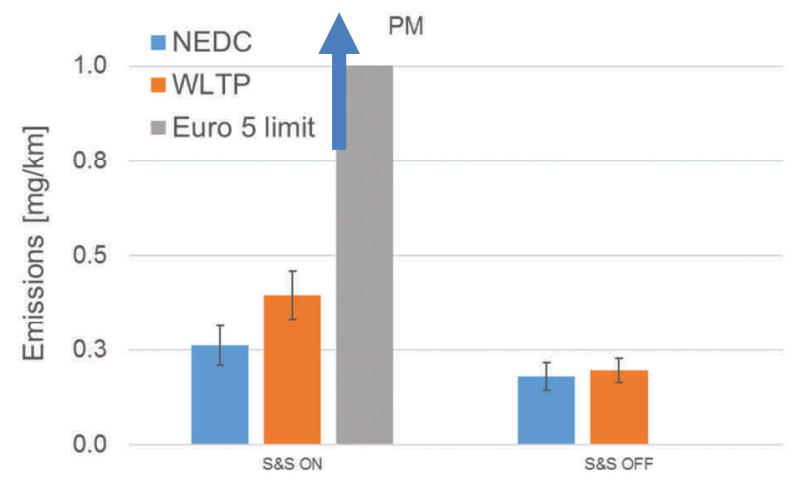

Fig. 5. PM emissions from vehicle 2. Note that the Euro 5 limit (4.5 $\mathrm{mg} / \mathrm{km}$ ) significantly exceeds the $\mathrm{y}$-axis of the figure, being roughly $\sim 10$ $\sim 20$ times the magnitude of the measured PM emissions

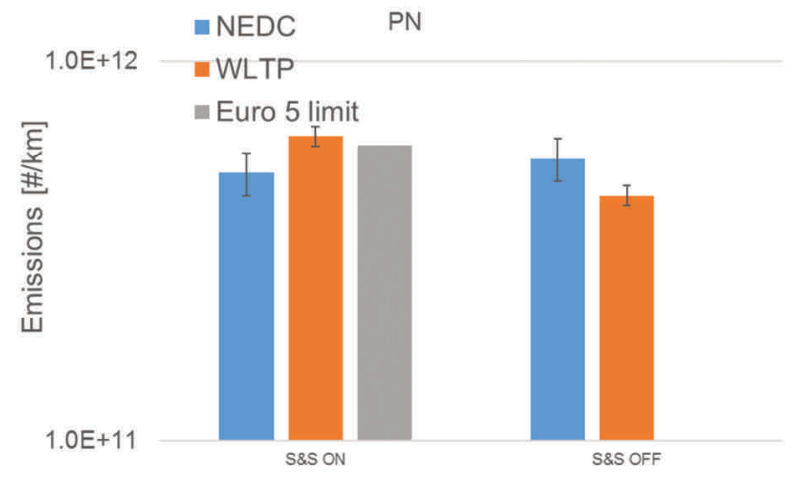

Fig. 6. PN emissions (solid particles only) from vehicle 2

Regarding PM, differences between the two test cycles were only significant where the Stop\&Start system was active; with the system deactivated, distance specific emissions were essentially indistinguishable. The PM "penalty" for the WLTP appears to be related to the reduced proportion of idling in that cycle compared to the NEDC and not to engine re-start events (of which there are fewer in the WLTP than in the NEDC). The situation for PN was broadly similar - higher emissions over the WLTP than the NEDC with Stop\&Start active; with Stop\&Start inactive there was some indication of lower emissions over the WLTP, but the difference was of questionable statistical significance. Somewhat surprisingly, the Stop\&Start system 
showed no statistically significant advantage regarding reducing legislative particulate emissions over the two test cycles; the emissions eliminated via engine shutdown at idle when using Stop\&Start appearing to be cancelled out by emissions from re-start events. However, it is worth repeating that the vehicle featured a DPF and so exhaust emissions do not reveal the full picture. In general, the low emissions levels of DPF-equipped CI engines make the viability of the gravimetric (PM) method questionable.

\subsubsection{Vehicle 3}

Vehicle 3 was a bi-fuel (petrol/CNG) vehicle, with CNG mode as the default startup option. However, when the temperature of the coolant is $<50^{\circ} \mathrm{C}$, startup occurs on petrol and switches over to CNG after approximately 10-20 seconds (depending on the ambient temperature and whether the engine is left to idle or is subject to load). Since solid particulate emissions from the combustion of $\mathrm{CNG}$ (where properly metered) are low $[10,19,22]$ emissions over the cold start test cycles used (NEDC, WLTP) were dominated by operation on petrol, even though it only accounted for roughly $0.5 \%$ to $1 \%$ of the engine operation time of the emissions test. A cold start (even at $23^{\circ} \mathrm{C}$ ) features a combination of factors which conspire to increase particulate emissions: cold metal surfaces and lubricant leading to unfavourable thermal conditions and high friction, use of petrol (rather than $\mathrm{CNG}$ ) and an enriched mixture $(\lambda<1)$.

In terms of the comparison between the two test cycles, there was a clear tendency for higher PM emissions over the WLTP, as shown in Figure 7. However, as Figure 8 shows, legislative PN emissions were virtually indistinguishable, with the difference not significant at the $95 \%$ confidence level, although the raw test results for the WLTP were slightly higher than those of the NEDC. In terms of comparisons to other studies measuring legislative particulate emissions from light-duty $\mathrm{CNG}$ vehicles, results obtained over the NEDC are study are very similar to those presented in [15]. In [19] particulate emissions (PN and PM) from CNG vehicles are reported to be at similar levels to CI with DPF at low and moderate speeds - a finding broadly confirmed by the results presented here, where emissions lay well within the Euro 5/6 Diesel limits.

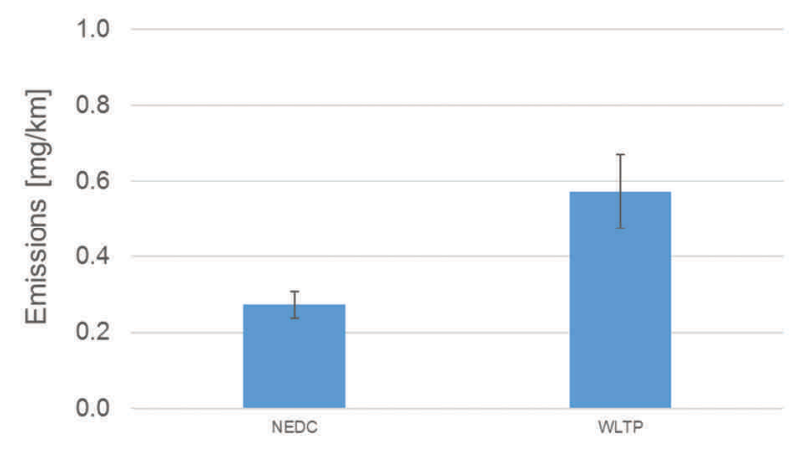

Fig. 7. PM emissions from vehicle 3

Despite the WLTP featuring higher speeds and a greater proportion of driving time at high speeds (say $>90 \mathrm{~km} / \mathrm{h}$ ), this fact did not translate into emissions levels high than CI with DPF (i.e. exceed the Euro 6 limits). In fact, as shown in Figure 9, the cold start phase (\#, 'Low') was a much greater contributor to $\mathrm{PN}$ emissions than the high speed phase (\#4, 'Extra High'). However, care must be taken in comparing these results with those of other studies, as the vehicle's startup strategy (when fuel switchover occurs; whether petrol is used at all when starting the engine at standard laboratory temperatures) may differ substantially from that of vehicles used in other studies.

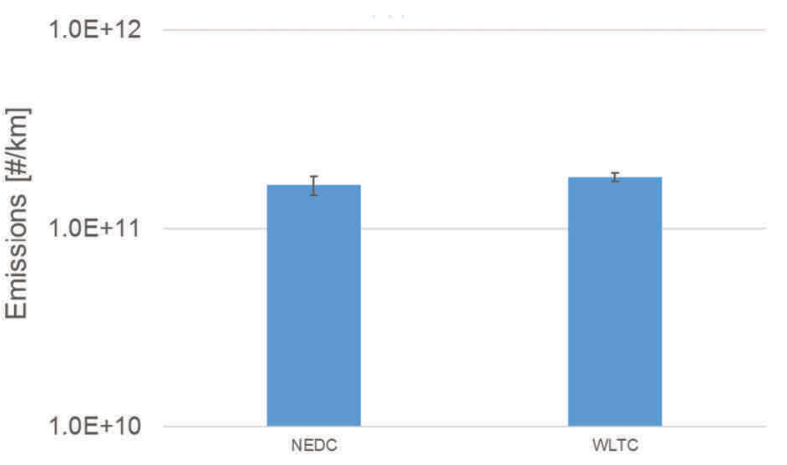

Fig. 8. PN emissions (solid particles only) from vehicle 3

In view of the fact that both cycles contain a cold start and a few seconds' operation on petrol, but that the WLTP's long length $(23.2 \mathrm{~km})$ "dilutes" this impact more than the NEDC $(11 \mathrm{~km})$, it is somewhat surprising that differences over the entire test cycles are so low (virtually indistinguishable). In an attempt to investigate further, emissions from the individual phases were considered Figure 9 presents the PN emissions per phase (and per test) for the two test cycles.

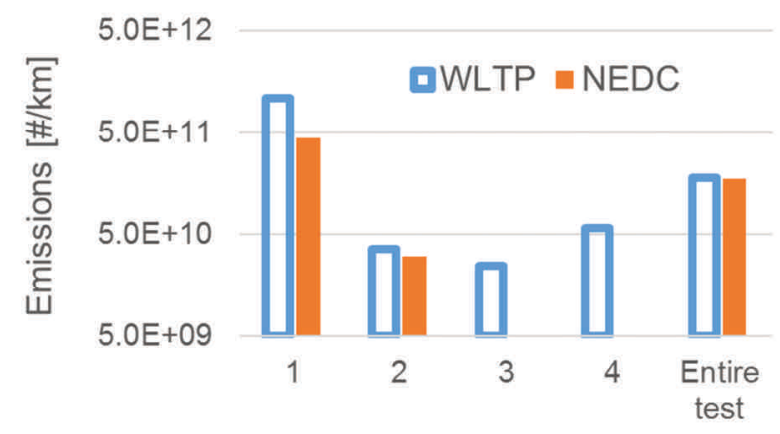

Fig. 9. PN emissions per phase and per test (solid particles only) for vehicle 3 (note that the NEDC consists of only two phases; note also the $\log _{10}$ scale)

The initial phase of both cycles caused the highest PN emissions, linked to the cold start and the fact that the engine starts on a fuel of greater particulate-forming propensity (i.e. petrol), thereafter running on $\mathrm{CNG}$. However, the distance covered by WLTP Low and the NEDC's UDC are unequal ( $\sim 3 \mathrm{~km}$ and $\sim 4 \mathrm{~km}$, respectively) and so the cold start and brief period of operation on petrol are divided by a smaller number of kilometres in the case of the WLTP. Further stages feature no engine operation on petrol whatsoever. The NEDC ends after phase two (EUDC), while the WLTP's third phase has low distance-specific emissions and the fourth phase has PN emissions around a tenth of those from the first phase. The result of the balance be- 
tween particles emitted and distance covered means that when the NEDC's two phases and the WLTP's 4 phases are considered, differences all but disappear and the differences in the results for the entire test are barely significant at the $95 \%$ confidence level. The presence of phases 2 and 3 in the WLTP (called 'Mid' and 'High', respectively) moderate the final WLTP PN result - particle emissions over those phases are modest, but the number of kilometres covered is relatively high $(\mathrm{Mid}+\mathrm{High}=11.9 \mathrm{~km}$, i.e. further than the entire NEDC). The High phase commences with the engine already warmed up, features only a single pull-away event, has very limited idling and its maximum speed is moderate $(97.4 \mathrm{~km} / \mathrm{h})$, with accumulated emissions divided by a distance of just over $7 \mathrm{~km}$ - for those reasons, that phase generated the lowest distance-specific PN results of all, causing PN emissions over the entire cycle to be lower than might be expected, based on the dynamic speed trace.

An AVL Microsoot sensor ${ }^{\mathrm{TM}}$ (MSS) was also used to investigate exhaust particulate emissions from vehicle 3 . This device uses a photoacoustic method to detect lightabsorbing particulates (i.e. the carbonaceous fraction) and convert the signal into a mass-based concentration (units: $\mathrm{mg} / \mathrm{m}^{3}$ ) [21], which can later be multiplied by the measured or calculated exhaust gas flow to yield a mass emission result. Figure 10 shows a comparison of the cumulative MSS particle mass concentration with the cumulative CPC particle count during a WLTP test. For both metrics, it is immediately apparent that the very first portion of the cycle generates the vast majority of particulate emissions. Despite the two devices using very different methods to measure particles and the imperfect overlap between the classes of particle measured by the two instruments, similarities are immediately apparent. As the initial portion of the driving cycle dominates the results returned by both instruments (at least for this test vehicle), Figure 11 shows real-time (noncumulative) results for the first 50 seconds of the cycle.

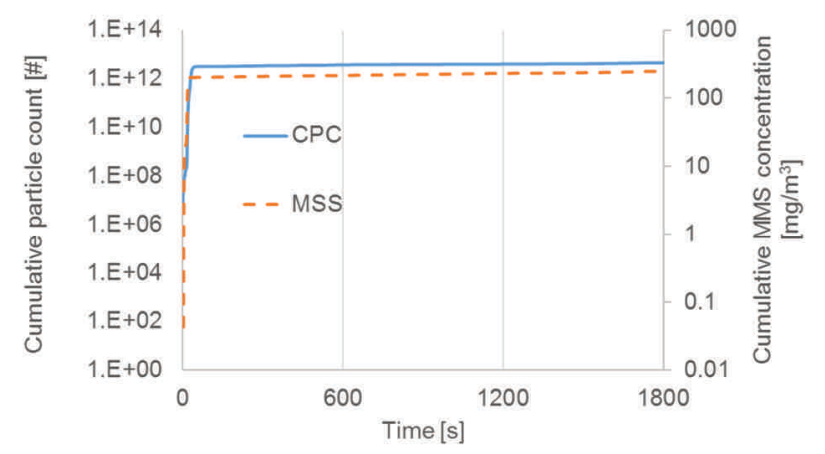

Fig. 10. Cumulative CPC (solid particles only) and MSS readings from vehicle 3 over the WLTP (note the $\log _{10}$ scales on both vertical axes)

The MSS shows two identifiable main peaks - one appearing to be related to the engine startup event and the other to the beginning of the first ramp of the WLTP (which contains the switchover from petrol to CNG, as well as load acceptance and multiple gear changes. The CPC trace shows the startup event and elevated emissions as the driver prepares to execute the first ramp, but the peaks are much less distinct than those returned by the MSS. The more direct response of the MSS is perhaps not unexpected, as the MSS measures directly at the tailpipe with limited internal dilution, while the CPC measures from the dilution tunnel (where the sample is already diluted), with substantial internal dilution (a setting of 1:300 was used for testing vehicle 3). The high Reynolds number of the dilution airexhaust mixture in the dilution tunnel means that brief peaks in particle emissions are likely to be flattened out to some extent. The MSS was able to measure the first $\sim 30$ to $\sim 50$ seconds of cycles executed in vehicle 3 well (with good test-to-test repeatability), but thereafter emissions are so low that the device is close to its lower limit of detection for the majority of rest of the cycle (whether NEDC or WLTP), even at very low internal dilution levels (e.g. 1:3). At points later in the test cycles where engine speed was high small peaks measured by the MSS were observed, but test-to-test variability of such peaks was high and their contribution to the overall MSS readings from the entire test was less than $2 \%$.

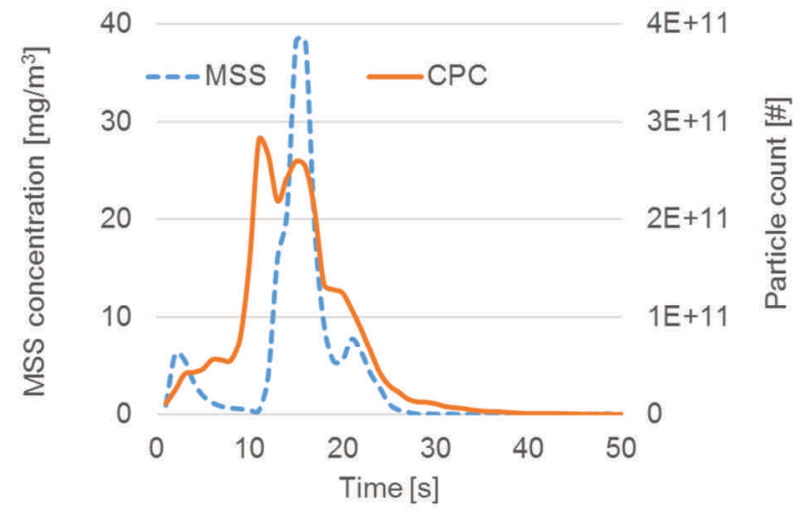

Fig. 11. CPC (solid particles only) and MSS readings over the first 50 seconds of the WLTP, for vehicle 3

Focusing on the first 50 seconds of the two cycles, there are obvious differences between the NEDC and WLTP as regards MSS results (Figures 12a and 12b).

When the four repeat tests are taken into account, testto-test variations in the first 10 seconds entirely cancel out, such that the startup event and the traces for first few seconds of idling (which are of course identical, regardless of the test cycle in progress) are identical. The first ramp of each cycle is clearly visible and the second peak begins almost simultaneously for both cycles (the difference in the duration of the initial idling time is only 1 second, i.e. within the permitted tolerance of the speed trace). The WLTP's first ramp involves significantly higher speeds than the NEDC's first ramp and uses gears as high as $3^{\text {rd }}$, while the NEDC's first ramp reaches only $15 \mathrm{~km} / \mathrm{h}$ and is driven entirely in $1^{\text {st }}$ gear. Integrating the MSS PM readings for the first 50 seconds of the two test cycles reveals that the WLTP produces approximately $40 \%$ more particulate quantifiable by MSS than the NEDC does; however, during the first 50 seconds the WLTP covers more than 5 times the distance covered by the first 50 seconds of the NEDC. (Fifty seconds is in fact an arbitrary cut-off point - other ranges could be considered.) The importance of the first 'ramp' (sub-trip) has been mentioned by other authors in the context of gaseous emissions [6, 9]. 

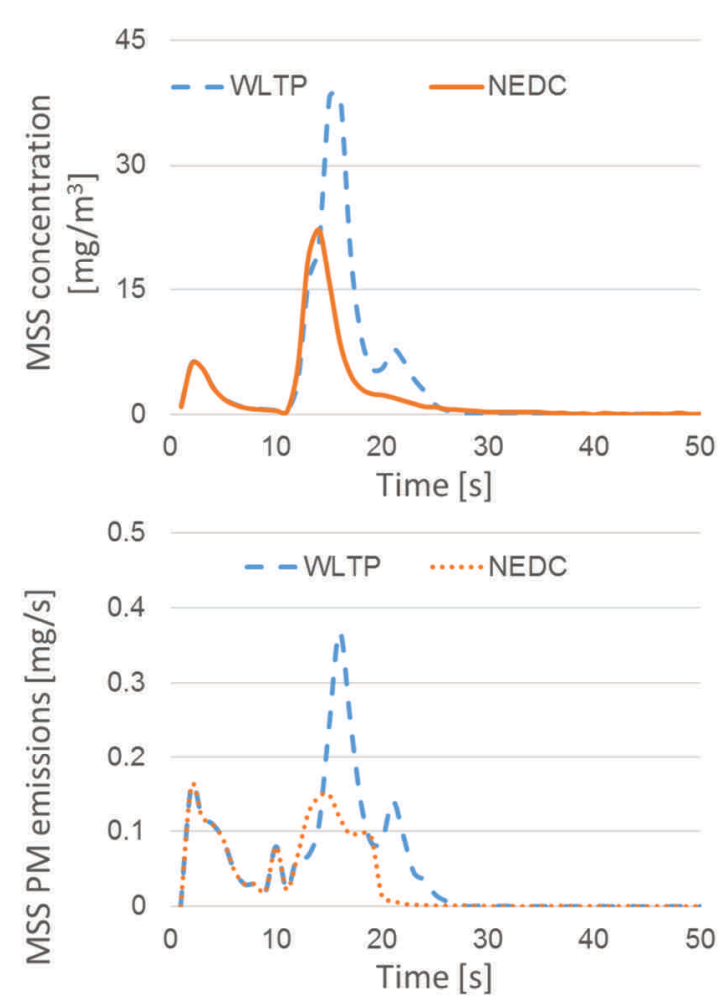

Fig. 12a: Raw MSS readings for the first 50 seconds of the NEDC and WLTP; and 12b: Calculated MSS emissions for the first 50 seconds of the NEDC and WLTP

The observed particle emission behaviour over the first ramp appears to be the result of a combination of effects caused by the cold start, the load associated with the driving trace and the fuel switchover and so it could be further investigated by running the WLTP and NEDC as thermally stabilised hot test cycles, in which case there would be no cold start, no warmup and no fuel switchover. Returning to Figures $11,12 \mathrm{a}$ and $12 \mathrm{~b}$, the persistence of relatively high MSS and CPC readings several seconds after the fuel switchover (which always occurred at around 13-15 seconds, during both driving cycles) point to a possible contribution from accumulated impinged liquid fuel. Figure $12 \mathrm{~b}$ shows the highest mass emissions measured by MSS over the WLTP at 16-17 seconds, after the fuel switchover. Here the authors speculate that the increased exhaust gas flowrate occurring over the first ramp on the WLTP was able to better purge the intake system, resulting in a higher post-fuel switcher over MSS peak over the WLTP than over the NEDC. These speculations provide further motivation to perform the hot testing mentioned in this paragraph.

MSS data were multiplied by the calculated exhaust gas flowrate and divided by the number of kilometres covered to yield an MMS PM result. These results were found to be consistently lower than the PM filter results, with the MSS results numerically equivalent to between $30 \%$ and $60 \%$ of the mass collected on the filter. The discrepancy in the mass results was lower over the WLTP than over the NEDC, possibly due to PM emissions over the former cycle being numerically higher. As the MSS measures only lightabsorbing PM components and as the fuel type (CNG) is a gaseous fuel not prone to PM formation, it is logical that MSS results are lower than filter results and that the corre- lation is weaker than that reported with other engine/fuel types (e.g. Diesel). The "additional" mass accumulating on the filter was likely due to the presence of water and adsorbed hydrocarbons. When the filters were reweighed following 24-26 hours' stabilization time, the results they yielded were somewhat closer to the MSS results, but the strength of the effect was small - a discrepancy of some $20 \%$ to $50 \%$ remained between the two sets of results, with high test-to-test variation.

Vehicle 3 was also tested at constant speed $(90 \mathrm{~km} / \mathrm{h}$ in $5^{\text {th }}$ gear, 3 minutes' sampling) as a hot test cycle commencing with the engine already running, following a thorough 42-minute warmup procedure (WLTC, 60 seconds' idling, acceleration to $90 \mathrm{~km} / \mathrm{h}$ and $90 \mathrm{~km} / \mathrm{h}$ in $5^{\text {th }}$ gear for 10 minutes). At $90 \mathrm{~km} / \mathrm{h}$ in $5^{\text {th }}$ gear with the powertrain, tyres, etc. very well warmed up, CNG consumption is at a low level and the engine does not consume any petrol at all; at constant speed there is no inertia to overcome and power demand is highly stable - all of these factors suggest that legislative PM and PN emissions should be low under such conditions. Furthermore, the CNG fuel used for testing had a higher methane number (96) and a chemical analysis revealed only trace levels of compounds containing carboncarbon double bonds and low levels of sulphur ( $\leq 8 \mathrm{ppm})$. Two repeat tests revealed that the MSS was unable to quantify meaningful exhaust emissions at such low levels and so the MSS results from these tests were discarded. PM and PN emissions were quantified successfully, with good agreement between the two tests, generating mean results of $0.04 \mathrm{mg} / \mathrm{km}$ and $3.45 \times 10^{10} \# / \mathrm{km}$. Both of these emissions results are roughly an order of magnitude below the emissions measured over the transient cold start driving cycles (NEDC/WLTP).

When correcting for the amount of CNG consumed per $\mathrm{km}, \mathrm{PM}$ results from the NEDC/WLTP and the constant speed cycle are almost identical, but this was not the case for PN, which was at a much lower level over the constant speed cycle, even when compensating for the reduced quantity fuel consumed per $\mathrm{km}$. This would imply a "lack" of smaller solid particles (which are the type counted by the $\mathrm{CPC}$ ). For engines burning high quality, low-sulphur CNG the contribution of the lubricating oil to PM and PN can be significant. Given that these PN emissions measured at constant speed are so low, it is interesting that the differences between the NEDC (which features multiple extended periods of constant speed driving) and the WLTP (which features virtually no constant speed driving) were so modest for vehicle 3 . Repeating the constant speed test with no warm up (i.e. from a cold start) and at higher load (for example, at $140 \mathrm{~km} / \mathrm{h}$ and/or applying chassis dyno slope simulation) could provide further insight here, but such data are not available for the time being.

It is also worth reiterating that the PN results presented here were measured in accordance with the EU legislative procedure, which specifically excludes all non-solid particles and solid particles of diameter $<23 \mathrm{~nm}$. Had particles of those kinds been measured for both the NEDC/WLTP cycles and the constant speed test, the ratio of the PN results might have been different. The PN "benefit" associated with combustion of CNG (compared to petrol) has been 
reported to reduce as the lower cut-off point of the CPC is reduced [15] - the low PN results found for vehicle 3 at constant speed may have been due to a shift in particle diameter which pushed a significant portion of the particles into the sub-23 nm range and thereby prevented their quantification. Quantifying the size distribution of the exhaust particulate and performing testing at different constant speeds could shed further light on these phenomena.

\subsubsection{Vehicle 4}

Vehicle 4 met the Euro 6 standard and its DPF-filtered $\mathrm{PM} / \mathrm{PN}$ emissions easily met Euro 6 limits over under all four test permutations of driving cycle and inertia setting. However, as Figures 13 and 14 show, in some cases the test conditions had a statistically significant impact on the result, although differences were extremely limited in the case of PM. Based on the number of tests performed, the results must be treated with some caution, but certain trends were observed.

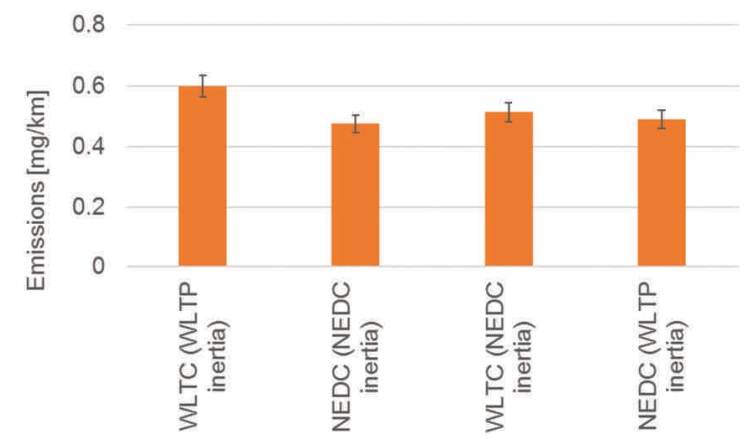

Fig. 13. PM emissions from vehicle 4 for the various test types performed

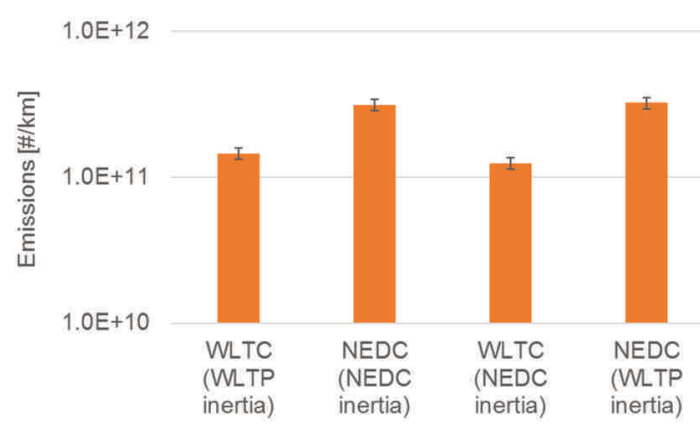

Fig. 14. PN emissions (solid particles only) from vehicle 4 for the various test permutations

The WLTP at the (higher) WLTP-compliant inertia setting caused the highest PM emissions of just under 0.6 $\mathrm{mg} / \mathrm{km}$. The NEDC caused the lowest PM emissions and the WLTC performed at the same inertia as the NEDC lay between the two. Performing the NEDC at the WLTP inertia increased the results somewhat, but statistically speaking results were the same as for the NEDC at the (lower) NEDC inertia. Statistically speaking there was no difference between the NEDC results and the WLTC (with NEDC inertia).

Analysing these results, it seems that the combination of the more demanding cycle (WLTC) and the higher inertia causes slightly increased PM emissions in comparison to the NEDC, but that changing only the driving cycle or only the inertia does not have a meaningful impact on post-DPF PM emissions over the entire test. Regarding PN, the situation was found to be rather different: results were lowest over the WLTC (marginally lower at the lower inertia setting) and results over the NEDC were unequivocally higher (with very little impact of the inertia used during execution of that cycle, which is not totally unexpected, given the many periods of constant speed that cycle contains). Here it appears clear that the test cycle has a greater impact than the inertia settings.

While the WLTC is a more demanding driving cycle with greater total demand for engine power, it also covers much more distance than the NEDC, causing greater dilution of the PN emissions associated with cold start. From the results presented in Figure 14, it can be concluded that for a given driving cycle, increasing the inertia increases PN emissions, but the effect appeared rather modest and of questionable statistical significance given the number of repeat tests performed (4). An increase in PN of $1.8 \%$ to $2.5 \%$ per $1 \%$ inertia increase has been reported for a vehicle with a direct-injection petrol engine [4]. For vehicle 4 the difference between the two inertia values was some $7 \%$ and the resulting increase in PN emissions over the WLTP was $15 \%$ (i.e. in line with the $2: 1$ ratio reported in [4], even though that study reported results from a different engine type). May et al. [17] varied the inertia of their test vehicles, but uncertainty was high and the results were confounded somewhat by the occurrence of DPF regeneration - however, increasing the inertia appeared to sometimes decrease PN emissions, in marked contrast to results presented here.

Over the NEDC the difference was a mere 3\%, supporting the theory that the multiple periods of constant speed and relatively gentle accelerations of that cycle minimize the impact of increases in inertia on legislative PN emissions. (Recall that the vehicle has no inertia to overcome at any constant speed - including at zero speed; constant speed and idle conditions account for almost $60 \%$ of the NEDC.)

Finally, it is worth underlining that exhaust emissions from this vehicle were DPF-filtered and that the full particulate budget would include the particulate (both PM and $\mathrm{PN}$ ) which accumulates in the DPF during the various tests performed.

\subsubsection{Overall observations from tests performed on vehicle 1-4}

It has been very clearly established that overall the WLTP and even its test cycle alone (WLTC) causes much higher $\mathrm{NO}_{\mathrm{x}}$ emissions than the NEDC, for a range of vehicle types (see $[9,16]$ and references therein). Emissions of other pollutants and $\mathrm{CO}_{2}$ /fuel consumption often show more limited changes [5]. The particulate emissions presented in this study showed both increases and decreases, depending on the vehicle in question.

While the WLTP specifies a driving cycle and road load simulation which are arguably much closer to real-world usage than the NEDC, it remains a laboratory cycle carried out under relatively favourable conditions - further testing of a broader range of vehicles is necessary to obtain a complete picture of legislative particulate emissions over the current and incoming driving cycles. A general point re- 
garding this study's test vehicles with manual transmissions (i.e. vehicles 1, 3 and 4) and their results obtained over the WLTP is that the gearshift strategy might have a significant impact [4]. While the calculated WLTP gearshifts employed in this study were in full compliance with the most recent version of [25], further investigations could be performed to investigate the impact of subtle differences in the gearshift points on particulate emissions, especially PN.

The current procedure for calculating the gearshifts makes use of a calculated vehicle-specific parameter for the lowest viable engine speed for gears 3 and higher (termed ' $n$ min drive'), a derived value and a concept which may be better suited to Diesel engines than to petrol engines [23, 24]. During accelerations commencing from a low engine speed, the value of this parameter determines when the gears are changed and is thereby crucial in determining engine load and speed (and the behaviour of the turbocharger, if present). The WLTP does permit some flexibility in terms of the application of safety margins, which would likely affect PN emissions to at least some extent.

As noted elsewhere [4], even for a well-defined speed trace with very narrow tolerances, the question of gears and their usage means that the engine speed-load coordinates occurring while meeting that speed trace are far from universal. Much effort has been expended on the derivation of the approach for calculating gearshifts, but the overall emphasis has been more on drivability and (within certain limits) engine load is maximised by using the highest possible gear at a given vehicle speed.

For a given vehicle operating at a given speed, there are sometimes three gears which could physically be used and often two gears which might be selected by an "average driver". Thus, the impact of the gearshift logic and the relationship between calculated gearshift values and their impact on particulate emissions occurring in the real world are topics worthy of dedicated investigation. Finally, it bears repeating that legislative emissions results are distance specific $[/ \mathrm{km}]$ and so a longer test cycle further dilutes the emissions associated with cold start.

\section{Upcoming changes and developments}

A highly important upcoming change for the EU and some other markets which broadly follow EU regulations (e.g. China and India) is that of incoming RDE requirements. Recently updated specifications for the EU test procedure mean that PN emissions will be measured for both Diesel and DISI vehicles, with a conformity factor of 1.5 applicable to the limit of $6.0 \times 10^{11} \# / \mathrm{km}$ which will apply to both engine types from September 2017, such that the limit is effectively $9.0 \times 10^{11} \# / \mathrm{km}$. However, a decision was also made to include (rather than explicitly exclude) emissions from the cold start event in the calculation process. This makes the application of GPFs virtually a certainty, as emissions must be low under a very wide range of engine operating conditions and ambient conditions, including at high speed and during and following cold start at low ambient temperature.

When the cold start is excluded from the results, RDE PN (and PM) results can be significantly lower than laboratory results from cycles containing a cold start; the inclusion of cold start emissions will change this tendency somewhat, although the fact that for RDE testing the cold start is divided by a very long distance (often 70-90 km; some 3-4 times the distance covered by the WLTC) remains relevant. This issue will most likely dominate the research agenda and scientific debate on the topic addressed in this paper in the EU for some time. Recent indications are that the EU test methodology for the measurement of PN will also be updated to measure solid particles not of diameter $>23 \mathrm{~nm}$, but of diameter $>10 \mathrm{~nm}$. Legislation has yet to be drafted, but investigations are underway. Part of the motivation for such a change is the fact that DISI engines generally produce smaller particles than Diesel engines and that the $23 \mathrm{~nm}$ cut-off was chosen with Diesel particulate in mind. A further consideration is that all other factors being equal, particle size is inversely proportional to toxicology and concern has been raised over the health impact of particles which are currently not measured.

In China there are indications that PFI vehicles will have to be tested for PN emissions and meet PN limits, with only CNG-fuelled vehicles being exempt. Naturally, the question arises as to whether such an approach might be adopted in other jurisdictions which already employ the PN metric as a standard-setting tool. Finally, there remains the prospect of the USA, Japan (and countries which follow regulations adopted in the aforementioned countries) adopting $\mathrm{PN}$ as a metric of control.

The USA has longstanding objections to PN concerning repeatability and the fact that only non-volatile particles are measured, yet Japan and perhaps some other countries could conceivably adopt the PN metric at some point in the next few years. The USA has specified extremely low PM limits of below $1 \mathrm{mg} / \mathrm{km}$, but further decreases in emissions might only be measurable using a number-based approach like PN.

\section{Conclusions \& summary}

This paper has briefly examined the current situation regarding exhaust emissions of particulate matter and their measurement and control, with an emphasis on the situation in the EU. To support this analysis, results obtained in an emissions laboratory were presented. The results of this experimental campaign revealed that overall, it is very difficult to generalize regarding particulate emissions from the vehicles tested, due to their varying engine and fuel types and the presence or absence of a dedicated filter (DPF).

Unlike certain other pollutants (chiefly $\mathrm{NO}_{\mathrm{x}}$ ) [24, 25], the legislative exhaust particulate emissions from the vehicles tested in this study were not radically changed when moving from the NEDC to the WLTP (even with the application of more demanding road load settings). In some cases, trade-off type behaviour is apparent, where PM can decrease and PN can increase (which is indeed physically possible, as for a given mass of fuel and lubricating oil turned into particulate, the number of particles can vary massively according to the size profile of those particles).

The filter-based PM method was shown to be of limited power in differentiating between test cycles and inertia settings - even when using one filter per test to maximize the payload. The PN count generated by the CPC was a more reliable tool with better sensitivity and it also has the 
advantage of higher resolution $(1 \mathrm{~Hz}$, or even $10 \mathrm{~Hz})$. The MSS was used for testing on a CNG-powered vehicle with low emissions and proved of use only for the cold start event and the first ramp of the test cycle. However, overall the measurement of emissions from vehicle $3(\mathrm{CNG})$ was carried out successfully, despite the legislative PM and PN and the MSS technique not being designed with CNGpowered engines in mind.
In conclusion, as regards upcoming changes, the most significant trends are the levelling of the playing field regarding testing requirements and emissions limits for Diesel and non-Diesel engines and RDE testing under a much wider range of ambient conditions and driving conditions.

\section{Nomenclature}

$\lambda$

stoichiometric air:fuel ratio

CF conformity factor

$\mathrm{CI}$ compression ignition

$\mathrm{CNG}$ compressed natural gas

CPC condensation particle counter

CVS constant volume sampling [system]

DOC diesel oxidation catalyst

DISI direct injection spark ignition [engine]

DPF diesel particulate filter

EU European Union

EUDC extra-urban driving cycle

FC fuel consumption

GPF gasoline particulate filter

GTR15 Global Technical Regulation No. 15 - the WLTP

inertia the setting applied on a chassis dynamometer to simulate the vehicle's resistance to acceleration; closely linked to vehicle mass

\begin{tabular}{|c|c|}
\hline NT & lean NOx trap \\
\hline MSS & AVL Microsoot sensor ${ }^{\mathrm{TM}}$ \\
\hline $\min$ & $\begin{array}{l}\text { ve minimum engine speed when gears } 3 \text { and } \\
\text { higher are engaged, according to the GTR15 }\end{array}$ \\
\hline NEDC & New European Driving Cycle \\
\hline $\mathrm{M}$ & particle mass \\
\hline $\mathrm{N}$ & particle number \\
\hline RDE & real driving emissions \\
\hline S\&S & stop\&start (idle stop) system \\
\hline SI & spark ignition \\
\hline TWC & three-way catalyst \\
\hline UDC & urban driving cycle (the first phase of the NEDC) \\
\hline WLTC & $\begin{array}{l}\text { worldwide harmonised light duty vehicles test } \\
\text { cycle }\end{array}$ \\
\hline II T & $\begin{array}{l}\text { worldwide harmonised light duty vehicles test } \\
\text { procedure }\end{array}$ \\
\hline
\end{tabular}

and gasoline vehicles. Transportation Research Procedia. 2016, 14, 3079-3088, doi:10.1016/j.trpro.2016.05.454.

[8] CHASE, R., DUSZKIEWICZ, G., RICHERT, J. et al. PM measurement artifact: organic vapor deposition on different filter media. SAE Technical Paper. 2004, 2004-01-0967, doi:10.4271/2004-01-0967.

[9] DEMUYNCK, J., BOSTEELS, D., DE PAEPE, M. et al. Recommendations for the new WLTP cycle based on an analysis of vehicle emission measurements on NEDC and CADC. Energy Policy. 2012, 49, 234-242, doi:10.1016/ j.enpol.2012.05.081.

[10] EASTWOOD, P. Particulate emissions from vehicles. ISBN: 978-0-470-72455-2, Wiley, Chichester 2008.

[11] GIECHASKIEL, B., SCHIEFER, E., SCHINDLER, W., et al. Overview of soot emission measurements instrumentation: from smoke and filter mass to particle number. $S A E$ Int. J. Engines. 2013, 6(1), 10-22, doi:10.4271/2013-010138 .

[12] KERN, B., SPIESS, S., RICHTER, J. Comprehensive gasoline exhaust gas aftertreatment, an effective measure to minimize the contribution of modern direct injection engines to fine dust and soot emissions? SAE Technical Paper. 2014.2014-01-1513, doi:10.4271/2014-01-1513.

[13] KHALED, I., PREMNATH, V. Comparison among DMS 500, EEPS SMPS, MSS, EC/OC, CPMA, using laboratory 'soot' particles. Cambridge Particle Meeting. July 3, 2015. www.cambridgeparticlemeeting.org/sites/default/files/ Presentations/2015/CPM_Khalek_2015_Comparison\%20 among\%20DMS\%20500\%20EEPS\%20SMPS\%20MSS\%20 ECOC\%20CPMA\%20using\%20laboratory\%20\%E2\%80\%9 Csoot\%E2\%80\%9D\%20particles.pdf (accessed 09.11.2015).

[14] KHALEK, I., KITTELSON, D., BREAR, F. Nanoparticle growth during dilution and cooling of diesel exhaust: exper- 
imental investigation and theoretical assessment. SAE Technical Paper. 2000, 2000-01-0515, doi:10.4271/2000-010515 .

[15] MAMAKOS, A., MANFREDI, U. Physical characterization of exhaust particle emissions from late technology gasoline vehicles. JRC report. 2012, 72196, doi:10.2788/32371.

[16] MAROTTA, A., PAVLOVIC, J., CIUFFO, B. et al. Gaseous emissions from light-duty vehicles: moving from NEDC to the new WLTP test procedure. Environmental Science \& Technology. 2015, 49(14), 8315-8322, doi: 10.1021/acs.est.5b01364.

[17] MAY, J., BOSTEELS, D., FAVRE, C. A comparison of light duty vehicle emissions over different test cycles and in real driving conditions. FISITA. 2014, F2014-CET-058.

[18] MERKISZ, J., PIELECHA J. Nanoparticle emissions from combustion engines. Springer. 2015, doi:10.1007/978-3319-15928-7.

[19] RISTOVSKI, Z.D., MORAWSKA, L., HITCHINS, J. et al. Particle emissions from compressed natural gas engines. Journal of Aerosol Science. 2000, 31(4), doi:10.1016/ S0021-8502(99)00530-3.

[20] SAFFARIPOUR, M., CHAN, T.W., LIU, F. et al. Effect of drive cycle and gasoline particulate filter on the size and morphology of soot particles emitted from a gasoline-directinjection vehicle. Environmental Science \& Technology. 2015, 49(19), 11950-11958, doi:10.1021/acs.est.5b02185.

[21] SCHINDLER, W., HAISCH, C., BECK, H. et al. A photoacoustic sensor system for time resolved quantification of diesel soot emissions. SAE Technical Paper. 2004, 2004-010968, doi:10.4271/2004-01-0968.

[22] SCHREIBER, D., FORSS, A., MOHR, M., DIMOPOULOS, P. Particle characterisation of modern CNG, gasoline

Piotr Bielaczyc, DEng. - Engine Research Department, BOSMAL Automotive Research and Development Institute Ltd in Bielsko-Biała.

e-mail:Piotr.Bielaczyc@bosmal.com.pl

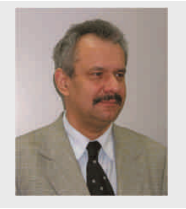

Joseph Woodburn, MSci. - Engine Research Department, BOSMAL Automotive Research and Development Institute Ltd in Bielsko-Biała.

e-mail: Joseph.Woodburn@bosmal.com.pl and diesel passenger cars. SAE Technical Paper. 2007, 2007-24-0123, doi:10.4271/2007-24-0123.

[23] STEVEN, H. Further modifications on the gearshift calculation tool. WLTP presentation. WLTP-DHC-17-02e, 2013, unece.org (accessed 20.12.2016).

[24] STEVEN, H. Status report about the work of the task force on gearshift issues. WLTP presentation. WLTP-15-04e, 2016, unece.org (accessed 20.12.2016).

[25] United Nations Economic Commission for Europe. Addendum 15: Global technical regulation No. 15 - Global technical regulation on the Worldwide harmonized Light vehicles Test Procedures. 28.10.2016, www.unece.org/fileadmin/ DAM/trans/main/wp29/wp29r-1998agr-rules/ECE-TRANS180a15app1e.pdf (accessed 18.11.2016).

[26] United Nations Economic Commission for Europe. Addendum 82: Regulation No. 83 Revision 5. 4.02.2015, www.unece.org/fileadmin/DAM/trans/main/wp29/wp29regs /R083r5e.pdf (accessed 4.03.2015).

[27] WEI, Q., AKARD, M., PORTER, S., NAKAMURA, H. The Effect of Drive Cycles on PM emission characteristics from a gasoline vehicle. SAE Technical Paper. 2009, 2009-011119, doi:10.4271/2009-01-1119.

[28] WHELAN, I., SMITH, W., TIMONEY, D., SAMUEL, S. The effect of engine operating conditions on engine-out particulate matter from a gasoline direct-injection engine during cold-start. SAE Technical Paper. 2012, 2012-01-1711, doi:10.4271/2012-01-1711.

[29] ZHANG, X., CHEN, L., LIANG, Z., SHUAI, S. Characterizing particulate matter emissions from GDI and PFI vehicles under transient and cold start conditions. Fuel. 2017, 189, 131-140, doi:10.1016/j.fuel.2016.10.055.

Andrzej Szczotka, DEng. - Engine Research Department, BOSMAL Automotive Research and Development Institute Ltd in Bielsko-Biała.

e-mail: Andrzej.Szczotka@bosmal.com.pl
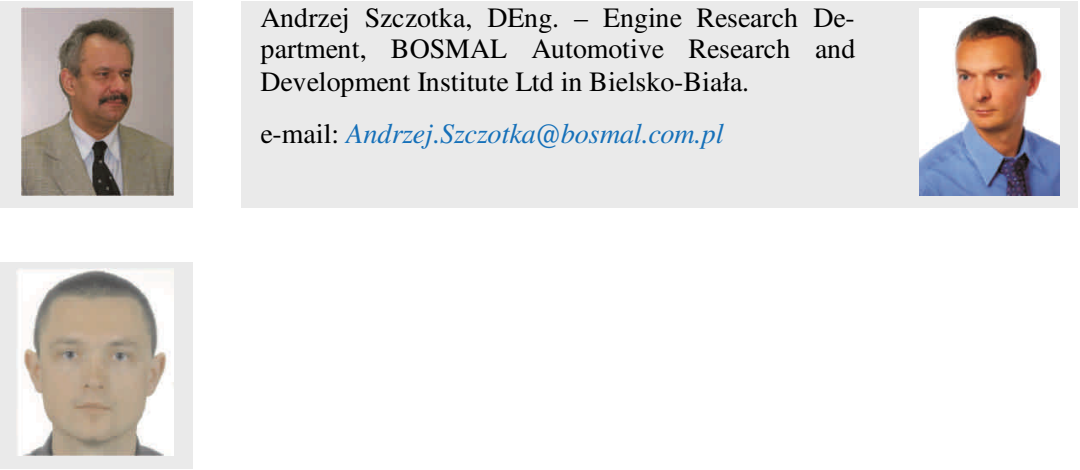